\title{
ОСТЕОИНДУКТИВНЫЕ СВОЙСТВА СЕКРЕТОМА МЕЗЕНХИМНЫХ СТВОЛОВЫХ КЛЕТОК ЧЕЛОВЕКА, ПОЛУЧЕННОГО С ИСПОЛЬЗОВАНИЕМ СИСТЕМЫ ДЛЯ АВТОМАТИЧЕСКОГО КУЛЬТИВИРОВАНИЯ КЛЕТОК
}

\author{
(с) 2020 г. С. А. Александрова ${ }^{1, *}$, Ю. А. Нащекина ${ }^{1}$, С. В. Надеждин ${ }^{2}$, С. А. Васильев ${ }^{3}$, Р. Р. Савченко \\ Л. А. Покровская ${ }^{4}$, М. И. Блинова ${ }^{1}$, Н. А. Михайлова ${ }^{1}$, М. Г. Хотин ${ }^{1}$ \\ ${ }^{1}$ Институт иитологии РАН, Санкт-Петербург, 194064 Россия \\ ${ }^{2}$ Белгородский национальный исследовательский университет, Белгород, 308015 Россия \\ ${ }^{3}$ Научно-исследовательский институт медицинской генетики \\ Томского национального исследовательского медицинского центра РАН, Томск, 634050 Россия \\ ${ }^{4}$ Национальный исследовательский Томский государственный университет, Томск, 634050 Россия \\ *E-mail: alekssvet2205@gmail.com
}

\begin{abstract}
С целью разработки технологии восстановительной терапии костных тканей получен секретом мезенхимных стволовых клеток (МСК) человека после остеогенной дифференцировки MCК линии FetMSC in vitro. Для получения стандартного образца секретома использовали бессывороточную кондиционированную среду (БКС), в которой культивировали большое число клеток FetMSC (до 700 млн). Все этапы клеточного процессинга проводили в автоматизированной системе CompacT SelectT (Sartorius, Великобритания). БКС концентрировали путем ультрафильтрации, затем подвергали диализу, высушивали в вакуумном ротационном испарителе. Остеоиндуктивные свойства концентрата БКС (КБКС) тестировали на клетках линии FetMSC при его добавлении в ростовую среду в разных концентрациях. Не было выявлено изменений морфологии клеток в процессе культивирования в присутствии КБКС. Анализ экспрессии транскрипционных факторов Runx2 и YAP1 (маркеров остеогенной дифференцировки клеток), с помощью иммунофлуоресцентного окрашивания и полимеразной цепной реакции в реальном времени (RT-PCR), показал повышение уровня их экспрессии в клетках в присутствии КБКС. Результаты позволяют сделать заключение о возможности использования КБКС, полученного от остеогенных МСК, для индукции дифференцировки других МСК. Полученные результаты могут быть использованы при разработке биомедицинских клеточных продуктов для восстановления костной ткани на основе секретома МСК.
\end{abstract}

Ключевые слова: мезенхимные стволовые клетки костного мозга человека, клеточная линия FetMSC, остеогенная дифференцировка, Runx2, YAP1, секретом, автоматизированная станция для культивирования клеток

DOI: $10.31857 / \mathrm{S} 0041377120040021$

В последние несколько десятилетий мезенхимные стволовые клетки (МСК), выделенные из тканей человека и культивируемые in vitro, активно изучаются с целью использования их в регенеративной медицине (Murphy et al., 2013; Mizukami, Swiech, 2018). Интерес к ним обусловлен высокой пролиферативной активностью, способностью к дифференцировке в различных направлениях, в частности, остеогенном, хондрогенном и адипогенном, а также способностью вырабатывать различные белки внеклеточного матрикса, ростовые факторы, цитокины и другие вещества, активно участвующие в регули-

Принятые сокращения: БКС - бессывороточная кондиционированная среда; ДС - дифференцировочная среда; КБКС концентрат БКС; КМ - костный мозг; МСК - мезенхимные стволовые клетки; RT-PCR - полимеразная цепная реакция в реальном времени; СЭК - сыворотка эмбрионов коров; PBS фосфатно-солевой буферный раствор. ровке клеточных функций, связанных с тканевым обновлением и репарацией (Pittenger et al., 2001; Da Silva Meirelles et al., 2009; Caplan, 2019). Регенеративная медицина костной ткани развивается в направлении создания трехмерных конструкций (графтов) с целью замещения патологических тканей или восстановления целостности кости. Для создания графтов используются материалы различной природы: костный матрикс животных, фосфаты кальция, полимеры, силикаты и др. Модификация материалов для придания им новых свойств, связанных с остеоиндукцией, достигается присутствием клеток (тканевая инженерия), белками внеклеточного матрикса, ростовыми факторами или генетическими конструкциями (Deev et al., 2015).

Активно обсуждаются подходы к выбору материалов и свойства каждого из этих элементов, а также целесообразность (экономичность) их применения. 
В качестве источника стволовых клеток рассматривают: аспираты костного мозга (KM) (его мононуклеарную фракцию); МСК из КМ после культивирования in vitro; МСК, направленные в остеогенную дифференцировку; МСК из различных тканевых источников (помимо КМ) (Rosset et al., 2014; Black et al., 2015; Stanovici et al., 2016). Использование стволовых клеток в составе тканеинженерных конструкций ставит вопрос стандартизации клеточного материала, учитывая различную активность клеток, а также рисков опухолевой трансформации после трансплантации таких конструкций. Было показано, что большинство клинических эффектов, наблюдаемых при трансплантации МСК, достигается в основном за счет вырабатываемых ими паракринных факторов. Поэтому во многих случаях МСК могут быть заменены на секретом клеток без существенной потери клинического эффекта (Timmers et al., 2008; Ionescu et al., 2012; Du et al., 2013).

В последние годы с помощью новых подходов транскриптомики и протеомики выявлено, что МСК синтезируют сложный комплекс биологически активных веществ (секретом), координирующий многие биологические функции клеток организма, такие как рост, деление, дифференцировку и клеточную гибель. Это сложный набор белковых молекул, выделяемых живыми клетками в межклеточное пространство. В секретоме МСК присутствует множество регуляторных молекул, что делает его перспективным продуктом для применения в медицине (Baglio et al., 2012; Pereira et al., 2014; Ivanova et al., 2016). В составе секретома МСК выделяют три основные фракции: малые молекулы, белки и экстраклеточные везикулы - экзосомы диаметром 50-200 нм и микровезикулы диаметром более 200 нм. Методом ядерномагнитного резонанса в составе секретома были обнаружены: аминокислоты, низшие спирты, липиды, микроРНК, органические кислоты, моносахариды, холин, пируват, тиамин, никотинамид, инозитол, пурины, мочевина и др. вещества (Pereira et al., 2014; Ivanova et al., 2016). МСК, выделенные из костного мозга, активно экспрессировали цитокины и факторы роста, такие как эндотелиальный фактор роста сосудов (VEGF), фракталкин (хемокин-CX3CL1), интерлейкины 6 и 8, онкоген, регулирующий рост (GRO) и др. (Roche, 2013). Конкретный состав секретома MCK варьирует в зависимости от донора и тканевого происхождения и меняется при определенных воздействиях, оказываемых на клетки. Во многих работах показано, что большое влияние на состав секретома оказывает клеточное микроокружение (Assoni et al., 2017; Kusuma et al., 2017). Следует заметить, что различные фракции секретома клетки могут проявлять различную биологическую активность на основе разных механизмов. Эти молекулы важны для нормальной жизнедеятельности организма при репарации тканей и могут применяться в биомедицине в качестве терапевтических факторов.
Анализ секретома МСК проводили в ряде работ, и он позволил выявить ряд белков, экспрессия которых меняется (увеличивается или снижается) в процессе остеогенной дифференцировки (Kristensen et al., 2012). В одной из работ (Kim et al., 2013) с помощью жидкостной хроматографии и масс-спектрометрии было идентифицировано 315 белков, из которых более 200 дифференциально экспрессировались в процессе остеогенеза (наблюдали усиление секреции белков, связанных с гомеостазом кальция, и снижение секреции белков, связанных с пролиферацией стволовых клеток). Протеомный состав МСК костного мозга человека (здоровые доноры) после индукции дифференцировки в течение 3 и 7 сут позволил выявить 52 белка, которые не экспрессировались ранее в популяции недифференцированных культивируемых клеток (Zhang et al., 2007), т.е. были специфичны только для остеогенной дифференцировки. В другой работе авторы (Kulterer et al., 2007) наблюдали преимущественную экспрессию транскрипционных факторов и генов, связанных с пролиферацией, в первые 4-5 сут, далее (до 14 сут) - генов, отвечающие за выработку внеклеточного матрикса и через 14 сут и далее) - генов, ответственных за минерализацию матрикса.

Особенностью МСК является высокая пролиферативная активность и способность к направленной дифференцировке в клетки мезенхимных тканей под влиянием определенных индукторов (Pittenger et al., 1999; Pittenger et al., 2001). На ранних этапах остеогенной индукции в клетках стимулируется экспрессия ряда генов и факторов транскрипции, которые связываются со специфическими цис-действующими элементами остеобластов и контролируют экспрессию генов, кодирующих основные белки костного матрикса (Ducy et al., 1997; Nakashima et al., 2002; Komori etal., 2011).

На молекулярно-генетическом уровне одним из известных ключевых регуляторов остеогенеза является транскрипционный фактор Runx2 (cbfa-1). Он активируется под воздействием TGF- $\beta 1$ и BMP-2, связывается со специфическими цис-действующими элементами остеобластов и контролирует экспрессию генов, кодирующих основные белки костного матрикса, например, остеокальцин. Белок YAP1 (yes-associated protein 1), известный также как YAP или ҮАР65, тоже транскрипционный фактор, был идентифицирован как функциональный партнер Runx в качестве ко-активатора транскрипции остеокальцина в процессе остеогенеза, активирует транскрипцию генов, участвующих в пролиферации клеток (Yagi et al., 1999).

В ряде исследований было показано, что использование факторов, вырабатываемых клетками в процессе дифференцировки и являющихся частью секретома, или непосредственное использование всей кондиционированной среды является сигналом для дифференцировки стволовых клеток поврежденных 
тканей (Yang et al., 2012; Zhong et al., 2019). Полученные знания привели к разработке нового направления в биомедицине, в котором используют белковые факторы или генетические конструкции, несущие гены таких факторов. Были созданы варианты генетических конструкций, использующие факторы роста или гормоны (ангиопоэтин-1, ВМР, эритропоэтин, паратиреоидный гормон, TGF- $\beta 1$, IGF, VEGF-A, bFGF и др.), а также транскрипционные факторы (Cbfa1, Runx2, SOX9 и др.). Эти факторы в составе графтов предназначены индуцировать стволовые клетки организма в направлении остеогенной дифференцировки, а также влиять на пролиферацию, хемотаксис и ангиогенез, приводя к ускорению репаративных процессов (Deev et al., 2015).

B ходе регенерации происходит множество процессов, и введение одного из факторов в место повреждения оказывается недостаточным для успешного восстановления ткани. Кроме того, системное введение ростовых факторов обычно является малоэффективным, а иногда и опасным вследствие их короткого времени жизни, неизбирательного биораспределения, потенциальной токсичности и риска канцерогенной активности. Альтернативой может являться инкапсуляция ростовых факторов в системы лекарственной доставки (микросферы, липосомы, гидрогели и др.) или введение их в скаффолды. Такое заключение биоактивных веществ решает несколько основных задач: целевую (таргетную) доставку ростовых факторов оптимальной концентрации внутрь имплантата, сохранение биологической активности молекул и контролируемое высвобождение веществ в течение необходимого периода времени (Luginbuehl et al., 2004; Chan et al., 2008; Porter et al., 2009; Sundelacruz, Kaplan, 2009).

В связи с этим приобрели значение технологии, связанные с использованием полноценного секретома МСК или его отдельных фракций для управления регенеративными процессами. Важной задачей при разработке медицинской технологии является получение достаточно большого количества секретома МСК и его стандартизация. Кроме того, секретом должен обладать остеоиндуктивными свойствами.

Цель настоящей работы - получение лиофилизированного концентрата бессывороточной кондиционированной среды (КБКС) от культивируемых MCK человека (линии FetMSC) после их дифференцировки в остеогенном направлении и исследование его остеоиндуктивных свойств по влиянию на морфологию клеток и их остеогенную дифференцировку.

\section{МАТЕРИАЛ И МЕТОДИКА}

Культивирование и индукция остеогенной дифференцировки МСК костного мозга человека с использованием автоматизированной станции CompacT SelecT. В работе использовали клеточную линию FetMSC (Коллекция культур клеток позвоночных Института цитологии РАН, Санкт-Петербург), полученную из МСК костного мозга эмбриона человека и охарактеризованную по всем основным параметрам (Крылова и др., 2012) в соответствии с минимальными требованиями Международного общества клеточной терапии, определяющими ее принадлежность к МСК (Dominici et al., 2006). Эти клетки хорошо адгезируют к пластику культурального сосуда и экспрессируют поверхностные маркеры CD44, CD73, CD90, CD105 и HLA-ABC; у них отсутствует экспрессия маркеров CD34, HLA-DR. Была продемонстрирована их способность дифференцироваться in vitro в остеогенном и адипогенном направлениях. Кариотипический анализ, проведенный на 12-14-м пассажах культивирования, подтвердил нормальный кариотип (46, XY) (Крылова и др., 2012).

Культивирование клеток FetMSC проводили в условиях чистых помещений Лаборатории биомедицинских технологий и испытаний с опытным производством Центра клеточных технологий ИНЦ РАН. Клетки культивировали в асептических условиях при контролируемых условиях: температура $\left(37^{\circ} \mathrm{C}\right)$, влажность $(98 \%)$ и состав газовой среды $\left(5 \% \mathrm{CO}_{2}\right)$. Для роста клеток использовали питательную среду DMEM/F12 (Gibco, США) с содержанием 10\% сыворотки эмбрионов коров (СЭК) (Gibco, США).

Для стандартизации всех этапов культивирования и получения БКС в работе использовали автоматизированную станцию для культивирования клеток CompacT SelecT (Sartorius, Великобритания) (рис. 1). При помощи роботизированной руки (манипулятора) производится перемещение флаконов с клетками между встроенным инкубатором и рабочей зоной, добавление питательных сред и компонентов, а также другие манипуляции с флаконами, которые необходимы при клеточном процессинге. Роботизированная рука наклоняет флаконы для слива среды или покачивает для перемешивания и ополаскивания клеток. Все манипуляции проводятся с соблюдением правил асептики и исключают внешнюю микробную контаминацию. Все флаконы штрих-кодируются. Система распознает маркировку флаконов и в соответствие с заданной программой производит манипуляции по пересеву клеток, замене среды и (или) добавления необходимых компонентов для культивирования в заданном объеме и концентрации. Состояние культивируемых клеток отслеживается в режиме реального времени, и на основе полученных данных проводятся необходимые манипуляции.

Автоматизированная станция позволяет в процессе культивирования контролировать ряд клеточных параметров. В робот встроены клеточный анализатор IncuCyte (Essen Bioscience, США) для оценки морфологии клеток и скорости пролиферациии, счетчик клеток ViCell (Beckman, США) для оценки жизнеспособности и подсчета общего числа клеток (во время пересева). Система CompacT SelecT с за- 


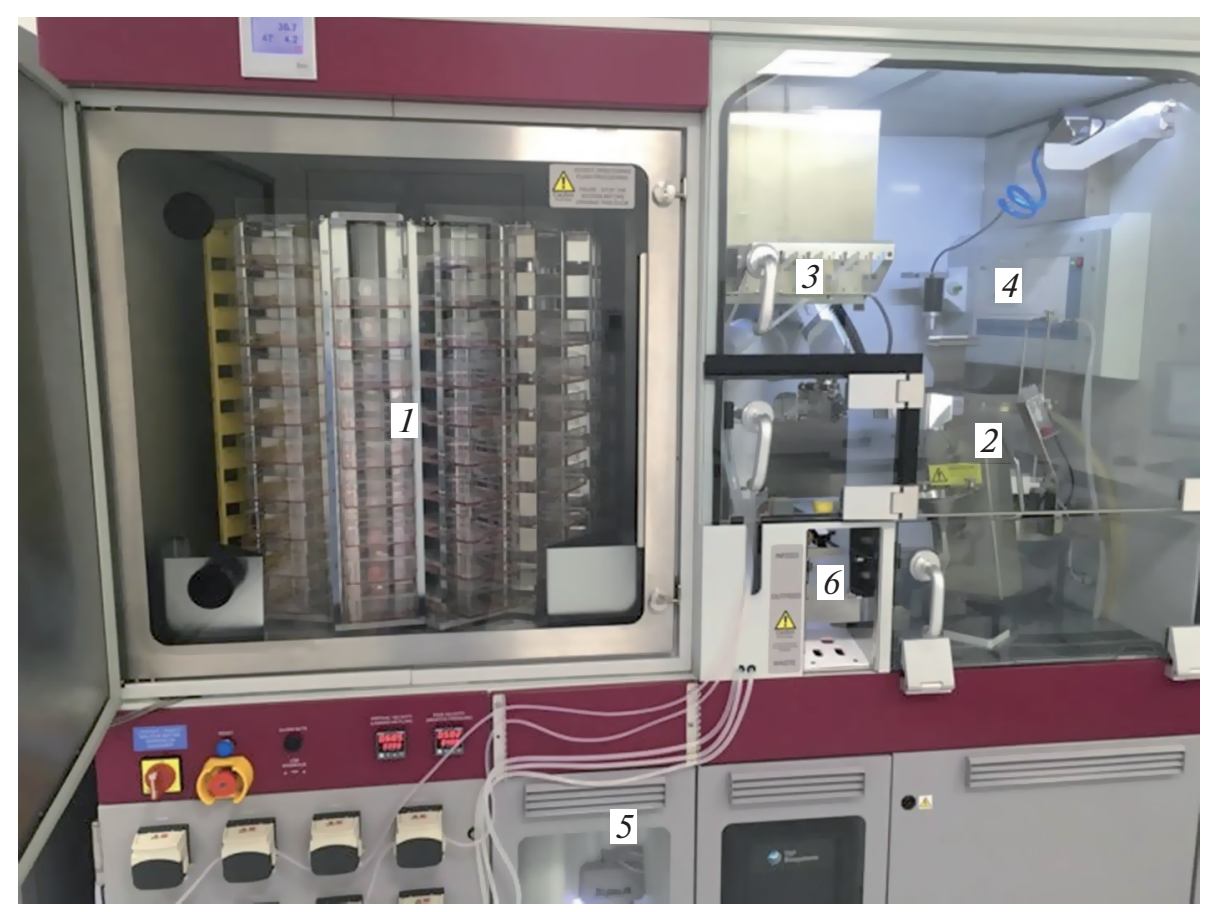

Рис. 1. Автоматизированная станция для культивирования и анализа клеток CompacT SelecT (Sartorius, Великобритания). Рабочие зоны автоматизированной станции: 1 - инкубатор с загруженными флаконами; 2 - рабочая зона роботизированной руки прибора для манипуляции с растворами и флаконами с клетками; 3 - зона розлива питательных сред и других жидкостей во флаконы; 4 - модуль IncuCyte (Essen Biosciences, США), 5 - счетчик клеток ViCell (Beckman, США); 6 - Шлюз для передачи в и из автоматизированной станции флаконов.

данной оператором периодичностью определяет их конфлюентность, а при достижении заданного значения производит пересев клеток. Кроме того, производится сбор кондиционированной среды в автоматическом режиме. Такой набор функций представляется оптимальным для выполнения задачи по стандартизации процесса масс-культивирования и сбора кондиционированной среды от большого объема клеток.

После размораживания и пассирования на флаконах 75 см $^{2}$ (T-75) клетки FetMSC переносили в автоматизированную станцию CompacT SelecT. Весь последующий клеточный процессинг проводили, используя разработанные алгоритмы для последовательных манипуляций. Последовательные этапы клеточного процессинга и замены сред при использовании CompacT SelecT представлены в табл. 1. Такой подход обеспечил стандартизацию процесса и однородность полученной популяции клеток. После наработки достаточного количества клеток культуральную среду заменяли на индукционную (дифференцировочную) среду (ДС), содержашую полную питательную среду DMEM/F12 с добавками дексаметазона (0.1 мкM), аскорбиновой кислоты(50 мкM) и $\beta$-глицерофосфата натрия (10 мМ) для стимуляции дифференцировки МСК в остеогенном направлении (Pittenger et al., 2001). Через 72 ч питательную среду удаляли, монослой клеток промывали 3 раза
PBS и меняли на бессывороточную ростовую среду DMEM/F12, в которой культивировали клетки в течение также 72 ч. Затем среду в автоматическом режиме в асептических условиях собирали в стерильную тару. Эту среду называли бессывороточной кондиционированной средой (БКС), а компоненты, секретируемые дифференцированными МСК, в БКС - секретомом остеогенных МСК, т.к. в процессе проведенных этапов индуцированные клетки секретировали в ростовую среду метаболиты, вырабатывающиеся в процессе остеогенной дифференцировки.

После сбора БКС клетки были сняты с поверхности культуральных флаконов для оценки их жизнеспособности с помощью счетчика клеток ViCell и клеточного анализатора, а также для оценки уровня экспрессии генов runx2 и уар1 транскрипционных факторов Runx2 и YAP1, принимающих участие в остеогенезе, методом полимеразной цепной реакции в реальном времени (RT-RCR) (методику см. ниже).

Приготовление концентрата среды, кондиционированной индуцированными МСК (КБКС). Собранную БКС центрифугировали при $1660 \mathrm{~g}$ в течение 10 мин. Полученный супернатант пропускали через фильтр с порами 0.22 мкм и затем концентрировали путем ультрафильтрации в тангенциальном потоке в системе Vivaflow 200 (Sartorius, Германия) с исполь- 
Таблица 1. Этапы клеточного процессинга при использовании автоматизированной станции CompacT SelecT

\begin{tabular}{|c|c|c|c|c|}
\hline Этап & Описание процедуры & Культуральная среда & $\begin{array}{c}\text { Манипуляции, проводимые } \\
\text { станцией CompacT SelecT }\end{array}$ & $\begin{array}{c}\text { Контролируемые } \\
\text { параметры }\end{array}$ \\
\hline $\begin{array}{l}\text { 1. Наращива- } \\
\text { ние клеток } \\
\text { линии FetMSC }\end{array}$ & $\begin{array}{l}\text { Масс-культивирование } \\
\text { клеток с целью получе- } \\
\text { ния } 50 \text { флаконов Т-175 } \\
\text { на пассаже } 5\end{array}$ & $\begin{array}{l}\text { ПС: DMEM/F12+10\% } \\
\text { СЭК }\end{array}$ & $\begin{array}{l}\text { Контроль КФ каждые } 12 \text { ч в } \\
\text { каждом флаконе с помощью } \\
\text { модуля IncuCуtе. При достиже- } \\
\text { нии КФ 85\% - пересев клеток } \\
1 \text { : 5. Контроль ЖС клеток и } \\
\text { подсчет их числа счетчиком } \\
\text { клеток ViCell . При пересеве } \\
\text { клеток: слив среды из флако- } \\
\text { нов, промывка РВS, добавле- } \\
\text { ние трипсина с покачиванием } \\
\text { флакона, добавление ПС, пере- } \\
\text { мешивание клеточной суспен- } \\
\text { зии пипетированием и перенос } \\
\text { в новые флаконы. }\end{array}$ & $\begin{array}{l}\text { ЖС клеток: 95- } \\
100 \% . \\
\text { Число клеток } \\
\text { на } 1 \text { флакон Т-175: } \\
\text { 12-16 млн шт. } \\
\text { Построение кривой } \\
\text { роста для каждого } \\
\text { флакона. }\end{array}$ \\
\hline $\begin{array}{l}\text { 3. Замена ДС на } \\
\text { БС }\end{array}$ & $\begin{array}{l}\text { Одновременный пере- } \\
\text { вод в БС 50-ти флако- } \\
\text { нов Т-175 с МСК через } \\
72 \text { ч индукции }\end{array}$ & БС: DMEM/F12 & $\begin{array}{l}\text { Оценка КФ перед заменой } \\
\text { среды (модуль IncuCyte). 3- } \\
\text { кратная промывка флаконов с } \\
\text { клетками РВS, добавление БС } \\
\text { и помещение флаконов в инку- } \\
\text { батор на } 72 \text { ч. }\end{array}$ & $\begin{array}{l}\text { КФ перед } \\
\text { заменой среды: } \\
80-90 \%\end{array}$ \\
\hline
\end{tabular}

Примечание. БКС - бессывороточная кондиционированная среда; БС - бессывороточная среда; ДС - дифференцировочная среда; ДФ - дифференцировка; ЖС - жизнеспособность; КФ - конфлюентность; ПС - питательная среда.

зованием мембранного модуля с порогом отсечения молекул с молекулярной массой 10 кДа. Полученный раствор подвергали диализу с использованием той же системы, добавляя деионизованную воду в емкость для пробы (диафильтрация). Очищенный от солей концентрат высушивали в вакуумном ротационном испарителе Rotavapor® R-210 (Buchi, Германия) и помещали в микроцентрифужную пробирку. Работы по получению КБКС были выполнены в СНИЛ “Клеточные, вспомогательные репродуктивные и ДНК технологии” НИУ “БелГУ”.
Лиофилизированный концентрат (КБКС) разводили в бессывороточной среде DMEM/F12 (Росмедбио, Россия) и стерилизовали пропусканием через фильтр с порами 22 мкм в асептических условиях, получая стоковый раствор с концентрацией 33.33 мг/мл. Для дальнейших исследований его добавляли в питательную среду (в отсутствие СЭК).

Прижизненное исследование морфологии МСК. Клетки линии FetMSC (4-5-го пассажей после декриоконсервации) рассевали в 24-луночные планшеты по 100 тыс. клеток в лунку и культивировали в течение 1 и 7 сут в стандартных условиях. Для иссле- 
Таблица 2. Последовательности и характеристика олигонуклеотидных праймеров

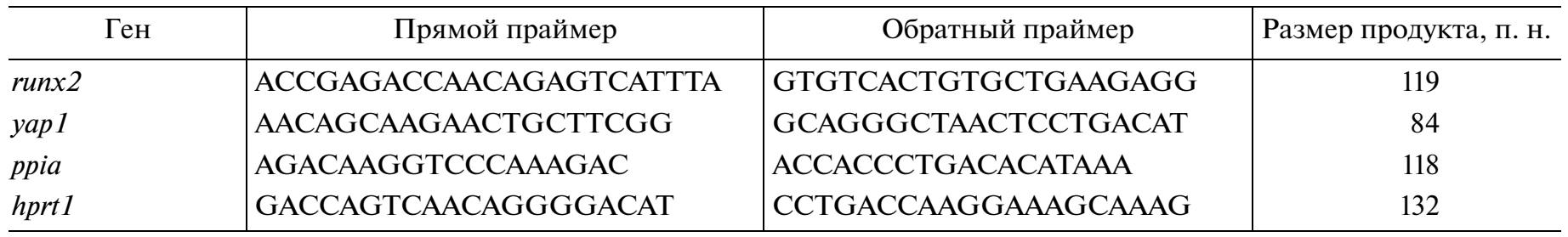

дования возможного влияния на морфологию клеток стоковый раствор КБКС добавляли в культуральную среду (не содержащую СЭК). Было протестировано два варианта - 0.33 и 0.66 мг/мл (конечная концентрация в среде). В качестве положительного контроля использовали FetMSC, культивируемые в среде DMEM/F12, содержащей 10\% CЭК (стандартные условия культивирования). Цифровую фотосъёмку клеточных культур в режиме реального времени проводили на инвертированном световом микроскопе Eclipse TS100 (Nikon, Япония).

Иммунофлуоресцентное выявление транскрипционных факторов. Клетки линии FetMSC рассевали на стекла, помещенные на дно лунок 24-луночных планшетов по 100 тыс. клеток на стекло и культивировали в течение 7 сут в стандартных условиях. Для исследования остеоиндуктивных свойств КБКС его добавляли в культуральную среду без СЭК в концентрации 0.33 или 0.66 мг/мл. В качестве положительного контроля использовали клетки, растущие в ДС, в качестве отрицательного контроля - клетки, растущие в стандартных условиях.

На 7-е сут культивирования ростовую среду сливали, клетки промывали PBS, фиксировали 30 мин в 10\%-ном растворе формалина (BioVitrum, Россия), еще раз промывали в PBS и пермеабилизовали в $0.1 \%$-ном растворе тритона X-100 в течение 15 мин при комнатной температуре. После этого клетки промывали в PBS и добавляли 1\%-ный бычий сывороточный альбумин (Sigma, США) на 30 мин для предотвращения неспецифического связывания антител. В качестве первичных антител использовали мышиные моноклональные антитела к белку Runx2 (ab76956) и кроличьи моноклональные антитела к YAP1 (ab205270; Abcam, Великобритания). На образец наносили 150 мкл первичных антител на 1 ч и промывали $\mathrm{PBS}$, затем помещали в 150 мкл вторичных антител на 1 ч при комнатной температуре в темноте. В качестве вторичных антител использовали, соответственно: флуоресцентно меченные (AlexaFluor® 488) козьи поликлональные антитела к IgG мыши (ab150113) и козьи поликлональные антитела (AlexaFluor® 594) к кроличьему IgG (ab150080) (Abcam, Великобритания). После инкубации со вторичными антителами образцы промывали PBS, затем на поверхность стекол наносили по 10 мкл среды для заключения препаратов в монтирующую среду DAPI FluoroShield (VectorLaboratories, США), содержащую интеркалирующий краситель DAPI для окраски ядер клеток. Фотографирование проводили на инвертированном конфокальном микроскопе $\mathrm{ZOE}^{\mathrm{TM}}$ FluorescentCellImager (США).

Полимеразная цепная реакция в реальном времени. Для выявления экспрессии генов runx 2 и уар 1 клетки линии FetMSC рассевали в 24-луночные планшеты по 100 тыс. клеток на лунку. Культивирование проводили в течение 3,7 и 14 сут в стандартных условиях. Для исследования остеоиндуктивных свойств КБКС его добавляли в культуральную среду без СЭК в концентрации 0.33 или 0.66 мг/мл. В качестве положительного контроля использовали клетки, растущие в ДС, и клетки остеосаркомы человека линии Hos (TE85, clone F5) из Коллекции культур клеток позвоночных Института цитологии РАН (СанктПетербург); для отрицательного - клетки, растущие в стандартных условиях.

Выделение РНК из клеток проводили с использованием реагента Лира (Биолабмикс, Россия), содержащего фенол и гуанидинтиоцианат, согласно рекомендациям фирмы-производителя. Обратную транскрипцию проводили с помощью набора реактивов OTM-MuLV-RH (Биолабмикс, Россия) по протоколу, рекомендованному производителем. Для проведения реакции RT-PCR использовали олигонуклеотидные праймеры к последовательностям генов runx2 и уар1, подобранные авторами исследования (табл. 2). В качестве референсного использовали праймеры к последовательностям гена рріа. Праймеры высокой степени очистки были синтезированы в OОО Биоссет (Россия, Новосибирск). RT-PCR проводили с использованием набора Maxima SYBRGreen (ThermoScientific, США) в амплификаторе AriaMx (AgilentTechnologies, США). Оценка уровня экспрессии генов была выполнена на базе Центра коллективного пользования научно-исследовательским оборудованием и экспериментальным биологическим материалом "Медицинская геномика" (Томск).

\section{РЕЗУЛЬТАТЫ И ОБСУЖДЕНИЕ}

Получение КБКС остеогенных МСК человека. Наработку клеточного материала (клеток линии FetMSC) проводили с помощью автоматизированной станции для культивирования клеток CompacT SelectT (рис. 1). Для стандартного культивирования FetMSC в рамках данной работы был разработан специальный алгоритм, который лег в основу программы для 
При пересеве

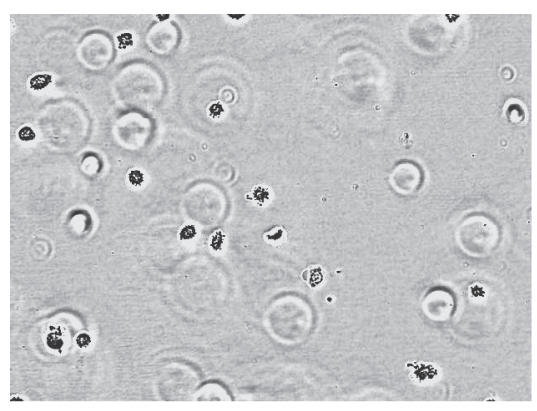

В среде без СЭК

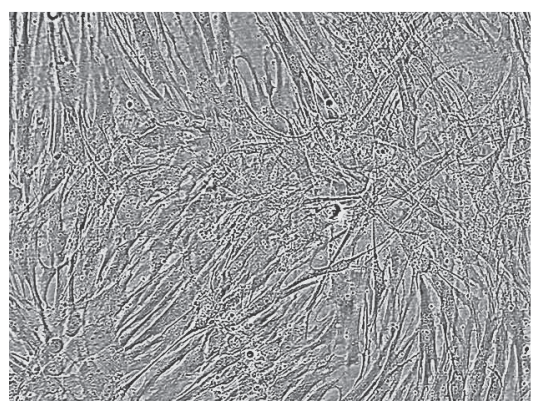

В ростовой среде

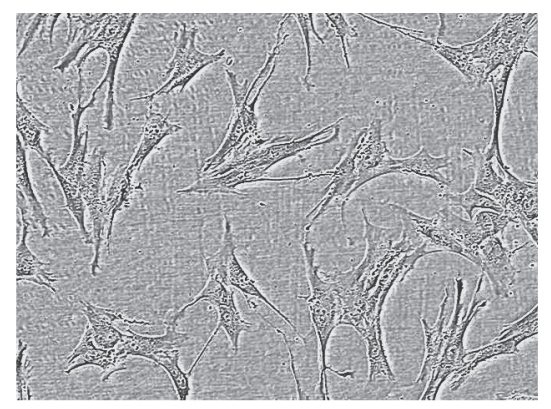

После сбора БКС

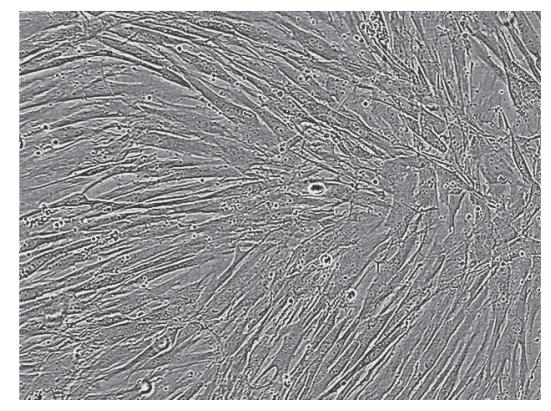

В остеогенной среде

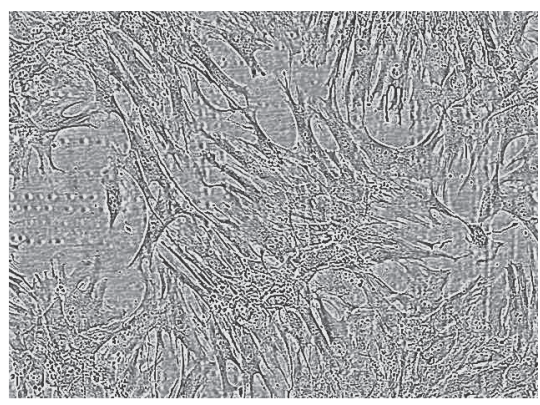

Кривая роста FetMSC

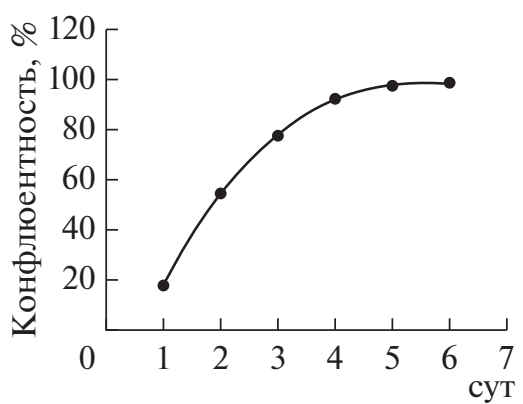

Рис. 2. Микрофотографии клеток линии FetMSC, полученные в процессе культивирования в робототизированной станции CompacT SelectT, и кривая роста клеток после последнего пересева. Видна фибробластоподобная морфология пересеянных клеток. Инвертированная микроскопия, ув. об.: 10×.

робота. Программа предполагала наработку 50 фла-

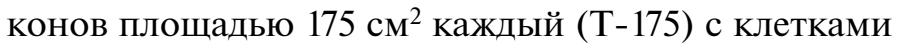
в течение 5 пассажей из одного флакона Т-75. Система производила пересев клеток при достижении конфлюентности 85\%. Для этого в алгоритм был включен регулярный (каждые 12 ч) контроль конфлюентности и морфологии клеток в культуре. Пересев клеток производили в соотношении $1: 5$, а замену среды - не реже одного раза в течение 3 сут. Для каждого из флаконов строили кривую роста, при пересеве клеток система проводила подсчет их общего числа. К пятому пассажу было наработано $7 \times 10^{8}$ клеток на 50 флаконах Т-175.

Во время всего процессинга жизнеспособность клеток с размером от 10 до 50 мк составляла 98$100 \%$. После получения 50 флаконов клеток с конфлюентностью 50-60\% система производила замену ростовой среды на индукционную (ДС) для дифференцировки МСК в остеогенном направлении, а после этапа дифференцировки (72 ч) - смену среды на бессывороточную, в которой культивировали клетки в течение 72 ч. Всего было собрано 1000 мл БКС.

Форма клеток в течение всего времени эксперимента оставалась фибробластоподобной, а клетки формировали монослой (рис. 2). Разрешение объектива прибора $(10 \times)$ позволяет различать форму клеток, а более тонкие морфологические структуры клеточных органоидов, к сожалению, оценить невозможно.

После сбора БКС были случайным образом выбраны два флакона, на которых непосредственно сразу после сбора среды клетки были обработаны лизирующим буфером для выделения РНК. Экспрессия гена runx2 на 3-и сутки в положительном контроле и клеточной линии Ноs была в 5 и 3 раза выше по сравнению с отрицательным контролем соответственно. При культивировании МСК в присутствии КБКС уровень экспрессии гена runx2 был лишь в 2 раза выше, чем в отрицательном контроле, но не достигал уровня экспрессии в положительном контроле. В то же время, экспрессия гена уар 1 в положительном контроле была в 2 раза выше, чем в отрицательном контроле, а в клеточной линии Hos не отличалась от отрицательного контроля. При культивировании МСК в присутствии КБКС экспрессия yap1 была в 1.7 раза выше по сравнению с отрицательным контролем, практически достигая соответствующего значения в положительном контроле.

\section{Остеоиндуктивные свойства полученного концентрата секретома (КБСК).}

Работы по получению лиофилизированного КБКС выполняли согласно рекомендациям, изложенным в инструкции производителя. В результате проведен- 

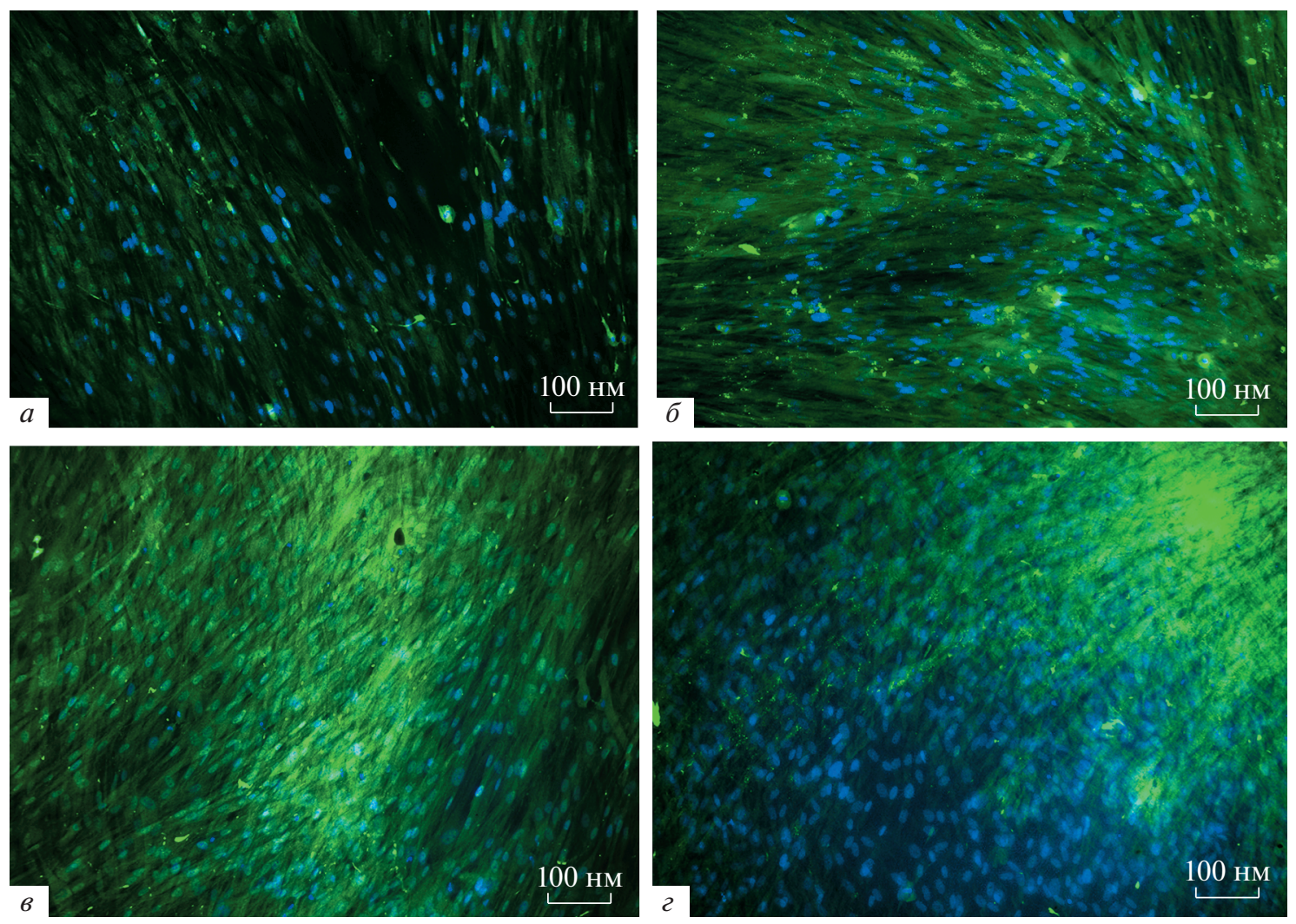

Рис. 3. Иммунофлуоресцентная окраска белка Runx2 (зеленый цвет) с помощью специфических моноклональных антител в клетках FetMSC после культивирования в ростовой $(a)$ и остеогенной (б) среде, а также в присутствии КБКС в концентрации 0.33 (в) и 0.66 (г) мг/мл в течение 7 сут. Ядра клеток окрашены DAPI (синий цвет). Конфокальная микроскопия. Об.: 20×.

ных работ был получен стерильный стоковый раствор КБКС с концентрацией 33.33 мг/мл. Для дальнейших исследований его добавляли в питательную среду (в отсутствие СЭК).

Влияние КБКС на морфологию МСК. Прижизненная оценка с помощью инвертированного микроскопа клеток, культивировавшихся в присутствии КБКС, не выявила явных различий между образцами (не показано). Клетки через 7 сут культивирования формировали плотный монослой. Можно предположить, что за это время еще не сформированы достаточно явные морфологические изменения структуры клеток, возникающие в процессе остеогенеза. Клетки активно пролиферировали.

Накопление факторов транскрипции Runx2 и YАР1в присутствии КБСК. Факторы транскрипции Runx2 и YAP1 в процессе остеогенной дифференцировки МСК человека идентифицировали путем непрямого иммунофлуоресцентного мечения антителами и визуализации окрашивания методом конфокальной микроскопии. Исследование проводили после культивирования клеток линии FetMSC в присутствии КБКС в ростовой среде. После связывания с антителами Runx2 на препаратах было выявлено зеленое свечение цитоплазмы клеток (рис. 3). Свечение наблюдали в клетках в присутствии КБКС в концентрации как 0.33 , так и 0.66 мг/мл в течение 7 сут примерно на одном уровне (рис. $3 в, 2)$. Этот уровень был ниже, чем в остеогенной среде (рис. 3б), но выше, чем в ростовой (рис. $3 a$ ). При этом окрашивание на препаратах выявлялось неравномерно, поэтому количественное сравнение сделать трудно.

После связывания с антителами к ҮАР1 характерное красное свечение на препаратах было выявлено в ядрах клеток (рис. 4). На препаратах клеток, которые культивировали в присутствии КБКС, превалирующее количество ядер имело красную окраску (рис. $4 b, 2)$ (в отличие от отрицательного контроля (рис. $4 a$ ), но было меньше, чем на клетках, культивировавшихся в остеогенной среде (рис. 4б).

Выявление экспрессии генов runx2 и уар1. Экспрессию генов runx2 и уap 1 в FetMSC оценивали методом RT-PCR (рис. 5). В результате было выявлено, что через 3 сут в опухолевой клеточной линии Hos экспрессия гена runx2 была выше (в 1.3-1.5 раза) по сравнению с отрицательным контролем. Экспрессия гена runx2 в положительном контроле (ДС) возрастала, начиная с 7-х сут культивирования (в 6 раз) по сравнению с отрицательным контролем и затем несколько снижалась к 14-м сут культивирования, оставаясь в 4 раза выше, чем в отрицательном контроле. Напротив, культивирование клеток в присут- 

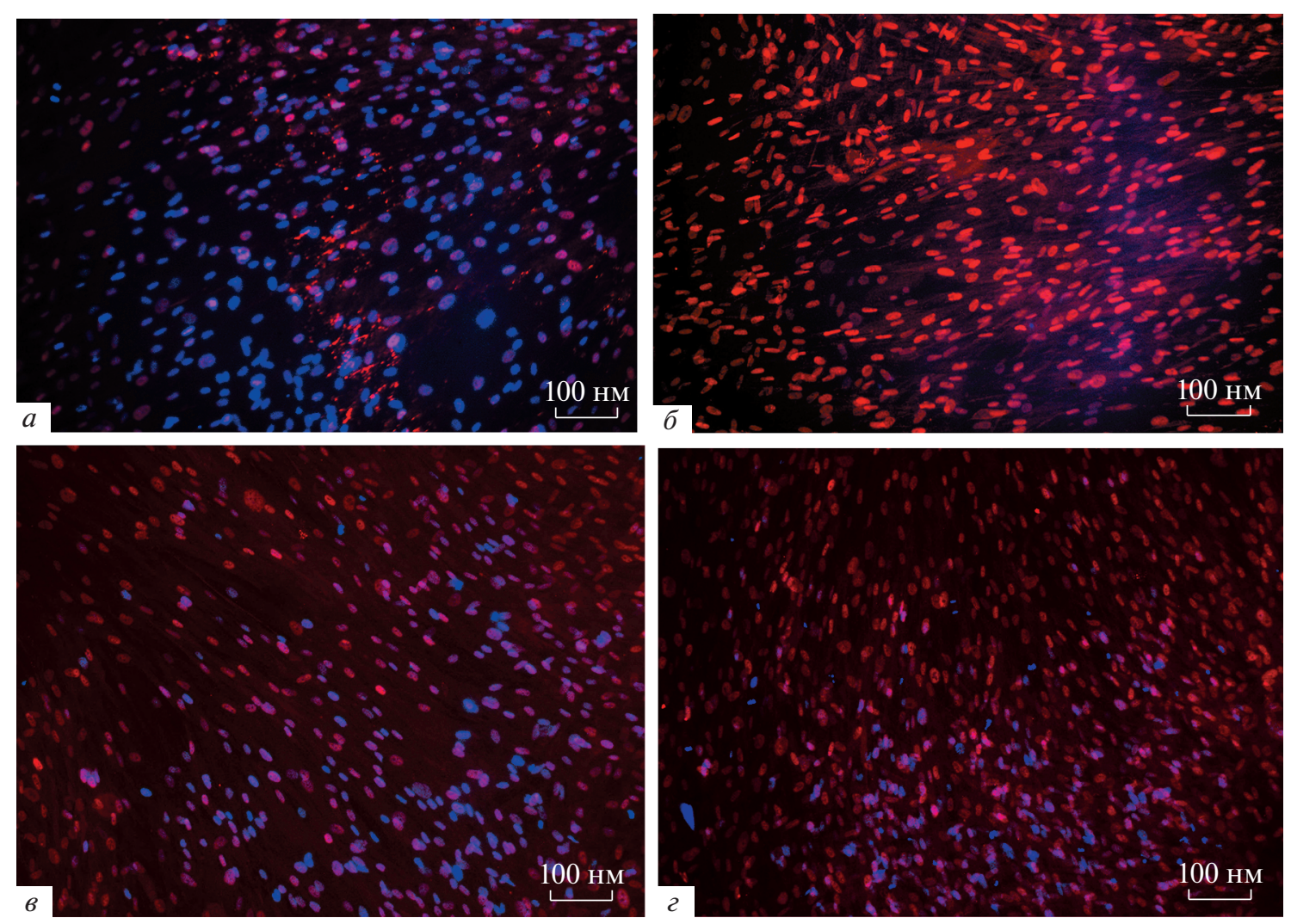

Рис. 4. Имунофлуоресцентная окраска белка ҮАР1 (красный ивет) с помощью специфических моноклональных антител в клетках FetMSC после культивирования в ростовой $(a)$ и остеогенной (б) среде, а также в присутствии КБКС в концентрации 0.33 (в) и 0.66 (г) мг/мл в течение 7 сут. Ядра клеток окрашены DAPI (синий цвет). Конфокальная микроскопия. Об.: $20 \times$.

ствии КБКС приводило к возрастанию экспрессии гена runx2 уже на 3-и сут (в 2.5 раза при концентрации КБКС 0.66 мг/мл и в 5 раз при концентрации КБКС 0.33 мг/мл). Максимальную экспрессию гена runx 2 наблюдали на сроке 7 сут (в 45 и в 12 раз выше отрицательного контроля при концентрации КБКС, соответственно, 0.66 и 0.33 мг/мл). На сроках 3 и 7 сут после добавления КБКС экспрессия гена runx2 превышала даже значения положительного контроля (ДС) (в 2-5 раз и 2-7 раз соответственно). Как и в положительном контроле, на 14-е сут эксперимента экспрессия гена runx2 снижалась, тем не менее, оставаясь в 3 раза выше, чем в отрицательном контроле. Динамика экспрессии гена runx 2 указывает на то, что КБКС обладает остеоиндуктивной активностью, которая превышает таковую для известных способов остеоиндукции.

Экспрессия гена уар 1 характеризовалась несколько отличной динамикой. В ДС (положительный контроль) она повышалась уже на 3-и сут культивирования в 1.9 раза с последующим повышением относительно отрицательного контроля к 7-м и 14-м сут в 2.3 и 3.9 раз соответственно. При культивировании клеток с КБКС экспрессия гена уар1 лишь незначительно повышалась относительно отрицательного контроля на 3-и сут (в 1.6 раза только при кон- центрации КБКС 0.66 мг/мл). На 7-е сут культивирования, наоборот, экспрессия гена уар 1 превышала соответствующее значение в ОК только для концентрации КБКС 0.33 мг/мл (в 3.2 раза относительно отрицательного контроля и в 1.4 раза относительно положительного контроля). Наконец, на сроке 14 сут экспрессия гена уар 1 превышала значения ОК для обеих концентраций КБКС (при 0.66 мг/мл - в 3.3, при 0.33 мг/мл - в 2.9 раз), будучи незначительно ниже значений для положительного контроля (в 1.1-1.3 раза). Таким образом, можно предполагать, что КБКС обладает несколько меньшим потенциалом индукции экспрессии гена уар 1 относительно известных способов остеоиндукции. Для второго референсного гена hprt1 получены сходные результаты.

\section{ЗАКЛЮЧЕНИЕ}

Как было выявлено в ряде исследований, секретом МСК включает сотни разнообразных регуляторных молекул, имеющих колоссальное значение для нормального функционирования клетки, а также играющих важную роль при возникновении патологических состояний. Следует заметить, что различные фракции секретома клетки могут проявлять различную биологическую активность на основе раз- 

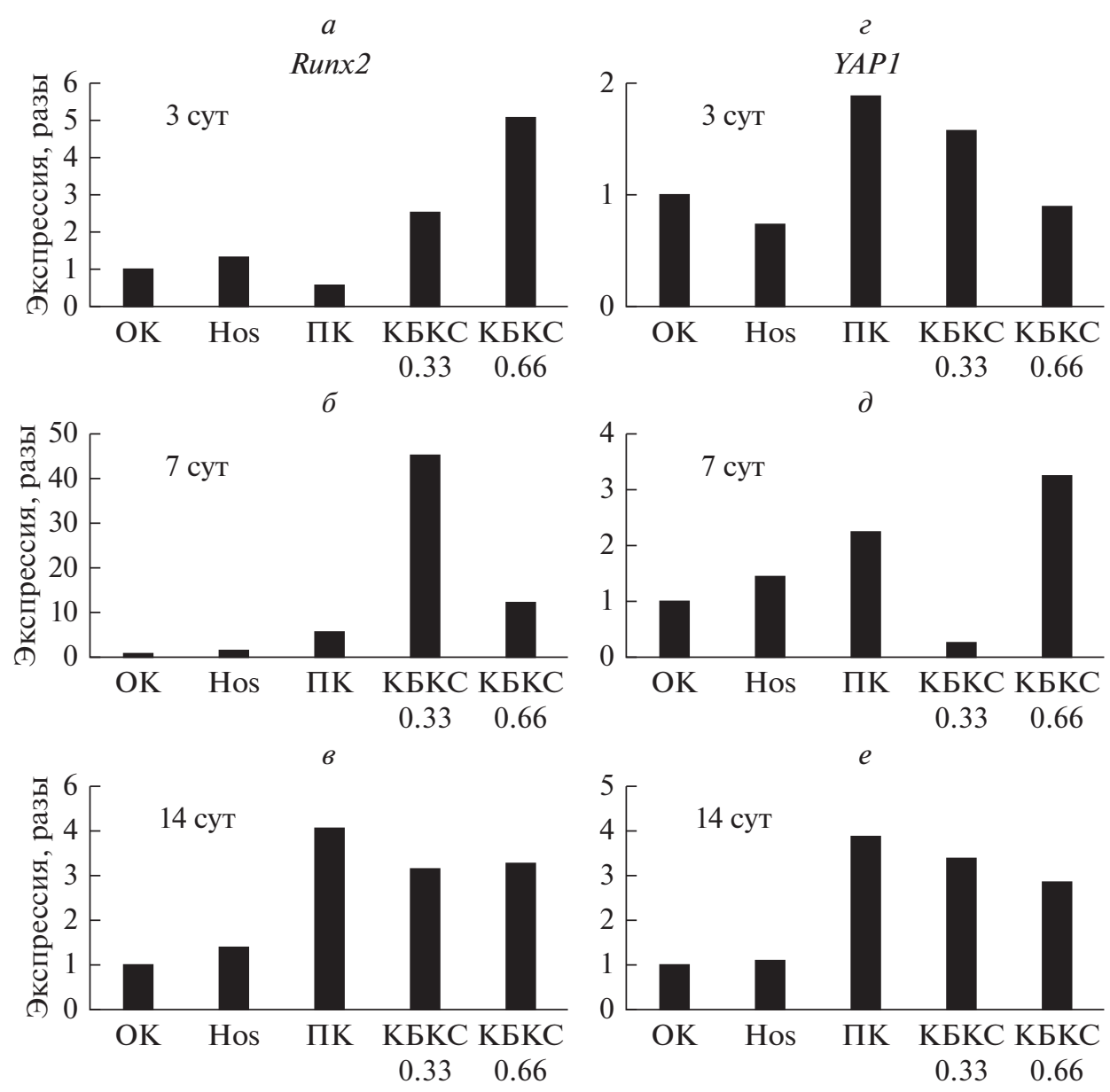

Рис. 5. Экспрессия генов runx2 $(a-8)$ и уap1 $(2-e)$ в клетках FetMSC в присутствии КБКС в ростовой среде $(0.33$ мг/мл или 0.66 мг/мл)в течение 3,7 и 14 сут. Показана кратность различий экспрессии генов относительно референсного гена рріа. ОК клетки, культивируемые в стандартных условиях (отрицательный контроль); ПК - в дифференцировочной среде, (положительный контроль). Hos - клетки опухолевой линии.

ных механизмов. Эти молекулы важны для нормальной жизнедеятельности организма при репарации тканей и могут применяться в биомедицине в качестве терапевтических факторов.

Перспективным является подход, заключающийся в инкапсуляции ростовых факторов в системы лекарственной доставки (микросферы, липосомы, гидрогели и др.) или введении их в скаффолды. Такое заключение биоактивных веществ решает несколько основных задач: целевую (таргетную) доставку ростовых факторов в оптимальной концентрации внутрь имплантата, сохранение биологической активности молекул, контролируемое высвобождение веществ в течение необходимого периода времени (Luginbuehl et al., 2004; Chan et al., 2008; Porter et al., 2009; Sundelacruz, Kaplan, 2009). Для создания такой технологии для целей медицины необходимо освоение технологии, позволяющей получить достаточно большое количество секретома МСК и стандартизировать этот процесс. Кроме того, секретом должен обладать остеоиндуктивными свойствами.
Метод масштабирования обычно используется в целях получения стандартной клеточной массы для дальнейшего исследования или банкирования. В этой работе метод был применен для изготовления экспериментального образца кондиционированной среды БКС, содержащей секретом остеогенных клеток. Разработанная технология включает не только наращивание клеточной массы, но и дальнейшее экспериментальное культивирование клеток в заданных условиях (кондиционирование среды). В результате проведенного исследования нами был разработан и апробирован алгоритм работы автоматизированной станции CompacT SelecT для наработки в стандартных условиях больших объемов клеток с целью получения БКС от культивируемых МСК человека линии FetMSC после их дифференцировки в остеогенном направлении.

Представленные результаты исследований in vitro влияния концентрата секретома (БКС) продемонстрировали его положительное влияние на способность МСК к остеогенной дифференцировке. Было 
показано, что разработанный метод позволяет сохранить компоненты клеточной активности, включая факторы роста, управляющие способностью клеток дифференцироваться в остеогенном направлении.

\section{БЛАГОДАРНОСТИ}

Авторы выражют благодарность научному руководителю Центра клеточных технологий Бирюч (ГК ЭФКО) Бурде Ю.Е. за предоставленное оборудование для получения концентрата БКС.

\section{ФИНАНСИРОВАНИЕ РАБОТЫ}

Работа выполнена при финансовой поддержке Минобрнауки России (соглашение № 14.575.21.0164, идентификатор RFMEFI57517X0164; работы по приготовлению КБКСК, имунофлуоресцентному выявлению транскрипционных факторов и проведению RT-PCR) и Российского фонда фундаментальных исследований (проект 19-290408; работы по культивированию и индукции остеогенной дифференцировки МСК костного мозга человека с использованием автоматизированной станции СотрасТ SelecT, а также прижизненное исследование морфологии МСК и выделение РНК).

\section{СОБЛЮДЕНИЕ ЭТИЧЕСКИХ СТАНДАРТОВ}

Эксперименты с использованием животных и человека не проводили.

\section{КОНФЛИКТ ИНТЕРЕСОВ}

Авторы заявляют об отсутствии конфликта интересов.

\section{СПИСОК ЛИТЕРАТУРЫ}

Крылова Т.А., Кольцова А.М., Зенин В.В., Мусорина А.С, Яковлева Т.К., Полянская Г.Г. 2012. Сравнительные характеристики новых линий мезенхимных стволовых клеток, полученных из эмбриональных стволовых клеток, костного мозга и крайней плоти человека. Цитология. T. 54. С. 5. (Krylova T.A., Koltsova A.M., Zenin V.V., Musorina A.S., Yakovleva T.K., Poljanskaya G.G. 2012. Comparative characteristics of new lines of mesenchymal stem cells derived from human embryonic stem cells, bone marrow, and foreskin. Cell Tiss. Biol. V. 6. P. 95.)

Assoni A., Coatti G., Valadares M. C., Beccari M., Gomes J., Pelatti M., Zatz, M. 2017. Different donors mesenchymal stromal cells secretomes reveal heterogeneous profile of relevance for therapeutic use. Stem Cells Devel. V. 26. P. 206.

Baglio S.R., Pegtel D.M., Baldini N. 2012. Mesenchymal stem cell secreted vesicles provide novel opportunities in (stem) cell-free therapy. Front. Phys. V. 3. P. 59.

Black C.R.M., Goriainov V., Gibbs D., Kanczler J., Tare R.S., Oreffo R.O.C. 2015. Bone Tiss. Engineering. Curr. Mol. Bio. Rep. V. 1. P. 132.

Caplan A.I. 2019. Mesenchymal stem cells in regenerative medicine. In: Principles of regenerative medicine. Acad. Press. P. 219.
Chan B.P., Leong K.W. 2008. Scaffolding in tissue engineering: general approaches and tissue-specific considerations. Eur. Spine J. V. 17. P. 467.

Da Silva Meirelles L., Fontes A.M., Covas D.T., Caplan A.I. 2009. Mechanisms involved in the therapeutic properties of mesenchymal stem cells. Cyt. Growth Factor Rev. V. 20. P. 419.

Deev R.V., Drobyshev A.Y., Bozo I.Y., Isaev A.A. 2015. Ordinary and activated bone grafts: applied classification and the main features. Biomed. Res. Int. V. 2015. P. 365050. https://doi.org/10.1155/2015/365050

Dominici M., Le Blanc K., Mueller I., Slaper-Cortenbach I., Marini F., Krause D., Deans R., Keating A., Prockop Dj., Horwitz, E. 2006. Minimal criteria for defining multipotent mesenchymal stromal cells. The International Society for Cellular Therapy position statement. Cytotherapy. V. 8. P. 315.

Du Z., Wei C., Cheng K., Han B., Yan J., Zhang M., Peng C., Liu $Y$. 2013. Mesenchymal stem cell-conditioned medium reduces liver injury and enhances regeneration in reducedsize rat liver transplantation. J. Surg. Res. V. 183. P. 907.

Ducy P., Zhang R., Geoffroy V., Ridall A.L., Karsenty G. 1997. Osf2/Cbfa1: a transcriptional activator of osteoblast differentiation. Cell. V. 89. P. 747.

Ionescu L., Byrne R.N., van Haaften T., Vadivel A., Alphonse R.S., Rey-Parra G.J., Weissmann G., Hall A., Eaton F., Thébaud B. 2012. Stem cell conditioned medium improves acute lung injury in mice: in vivo evidence for stem cell paracrine action. Am. J. Physiol. Lung. Cell. Mol. Physiol. V. 303. P. 967. https://doi.org/10.1152/ajplung.00144.2011

Ivanova G., Pereira T., Caseiro A.R., Georgieva P., Maurício A.C. 2016. Metabolomic and proteomic analysis of the mesenchymal stem cells' secretome. In: Metabolomics-fundamentals and applications. InTechIntechOpen. eBook. https://doi.org/10.10.5772/66101

Kim J.M., Kim J., Kim Y.H., Kim K.T., Ryu S.H., Lee T.G., Suh P.G. 2013. Comparative secretome analysis of human bone marrow-derived mesenchymal stem cells during osteogenesis. J. Cell. Phys. V. 228. P. 216.

Komori T. 2011. Signaling networks in RUNX2-dependent bone development. J. Cell Biochem. V. 112. P. 750.

Kristensen L.P., Chen L., Nielsen M.O., Qanie D.W., Kratchmarova I., Kassem M., Andersen J.S. 2012. Temporal profiling and pulsed SILA Clabeling identify novel secreted proteins during ex vivo osteoblast differentiation of human stromal stem cell. Mol. Cell. Proteomics. V. 11. P. 989.

Kulterer B., Friedl G., Jandrositz A., Sanchez-Cabo F., Prokesch A., Paar C., Scheideler M., Windhager R., Preisegger K.H., Trajanoski $Z$. 2007. Gene expression profiling of human mesenchymal stem cells derived from bone marrow during expansion and osteoblast differentiation. BMC Genomics. V. 8. P. 70.

Kusuma G.D., Carthew J., Lim R., Frith J.E. 2017. Effect of the microenvironment on mesenchymal stem cell paracrine signaling: opportunities to engineer the therapeutic effect. Stem Cells Dev. V. 26. P. 617.

Luginbuehl V., Meinel L., Merkle H.P., Gander B. 2004. Localized delivery of growth factors for bone repair. Eur. J. Pharm. Biopharm. V. 58. P. 197.

Mizukami A., Swiech K. 2018. Mesenchymal stromal cells: From discovery to manufacturing and commercialization. 
Stem Cells Int. V. 2018. ArticleID 4083921.

https://doi.org/10.1155/2018/4083921

Murphy M.B., Moncivais K., Caplan A.I. 2013. Mesenchymal stem cells: environmentally responsive therapeutics for regenerative medicine. Exp. Mol. Med. V. 45. P. e54. https://doi.org/10.1038/emm.2013.94

Nakashima K., Zhou X., Kunkel G., Zhang Z., Deng J.M., Behringer R.R, de Crombrugghe B. 2002. The novel zinc fingercontaining transcription factor osterix is required for osteoblast differentiation and bone formation. Cell. V. 108. P. 17.

Pereira T., Ivanova G., Caseiro A.R., Barbosa P., Bártolo P.J., Santos J.D., Luís A.L., Maurício A.C. 2014. MSCs conditioned media and umbilical cord blood plasma metabolomics and composition. PloS One. V. 9. P. e113769. https://doi.org/. 0113769 https://doi.org/10.1371/journal.pone

Pittenger M.F., Mackay A.M., Beck S.C., Jaiswal R.K., Douglas R., Mosca J.D., Moorman M.A., Simonetti D.W., Craig S., Marshak D.R. 1999. Multilineage potential of adult human mesenchymal stem cells. Science. V. 284. P. 143.

Pittenger M.F., Mbalaviele G., Black M., Mosca J.D. Marshak D.R. 2001. Mesenchymal stem cells. In: Human cell culture. The Netherlands Kluwer: Acad. Publishers. V. 5. P. 189.

Porter J.R., Ruckh T.T., Popat K.C. 2009. Bone tissue engineering: A review in bone biomimetics and drug delivery strategies. Biotechnol. Prog. V. 25. P. 1539.

Roche S. D'Ippolito G., Gomez L.A., Bouckenooghe T., Lehmann S., Montero-Menei C.N., Schiller P.C. 2013. Comparative analysis of protein expression of three stem cell populations: Models of cytokine delivery system in vivo. Int. J. Pharm. V. 440. P. 72.
Rosset P., Deschaseauxc F., Layrolle P. 2014. Cell therapy for bone repair. Orth. Traum: Surg. Res. V. 100. P. 107.

Stanovici J., Le Nail L.-R., Brennana M.A., Vidalab L., Tricheta V., Rosset P., Layrolle P. 2016. Bone regeneration strategies with bone marrow stromal cells in orthopaedic surgery. Curr. Res. Transl. Med. V. 64. P. 83.

Sundelacruz S., Kaplan D.L. 2009. Stem cell-and scaffold based tissue engineering approaches to osteochondral regenerative medicine. Semin. Cell Dev. Biol. V. 20. P. 646.

Timmers L., Lim S.K., Arslan F., Armstrong J.S., Hoefer I.E., Doevendans P.A., Piek J.J., El Oakley R.M., Choo A., Lee C.N., Pasterkamp G., de Kleijn D.P. 2008. Reduction of myocardial infarct size by human mesenchymal stem cell conditioned medium. Stem Cell Res. V. 1. P. 129.

Yagi R., Chen L.F., Shigesada K., Murakami Y., Ito Y. 1999. A WW domain-containing yes-associated protein (YAP) is a novel transcriptional co-activator. EMBO J. V. 18. P. 2551.

Yang Y.-Q., Tan Y.-Y., Wong R., Wenden A., Zhang L.-K., Rabie A.B.M. 2012. The role of vascular endothelial growth factor in ossification. Int. J. Oral Science. V. 4. P. 64.

Zhang A.-X., Yu W.-H., Ma B.-F., Yu X.-B., Mao F.F., Liu W., Zhang J.-Q., Zhang X.-M., Li S.-N., Li M.-T., Lahn B.T., Xiang A.P. 2007. Proteomic identification of differently expressed proteins responsible for osteoblast differentiation from human mesenchymal stem cell. Mol Cell Biochem. V. 304. P. 167.

Zhong S., He X., Li Y., Lou X. 2019. Conditioned medium enhances osteogenic differentiation of induced pluripotent stem cell-derived mesenchymal stem cells. Tiss. Eng. Regen. Med. V. 16. P. 141.

\title{
OSTEOINDUCTIVE PROPERTIES OF HUMAN MESENCHYMAL STEM CELLS SECRETOME OBTAINED BY AUTOMATIC CELL CULTIVATION SYSTEM
}

\author{
S. A. Aleksandrova ${ }^{a, *}$, Y. A. Nashchekina ${ }^{a}$, S. V. Nadezhdin ${ }^{b}$, S. A. Vasilyev ${ }^{c}$, R. R. Savchenko ${ }^{c}$ \\ L. A. Pokrovskaya ${ }^{d}$, M. I. Blinova ${ }^{a}$, N. A. Mikhailova ${ }^{a}$, and M. G. Khotin ${ }^{a}$ \\ ${ }^{a}$ Institute of Cytology Russian Academy of Sciences, St. Petersburg, 194064 Russia \\ ${ }^{b}$ Belgorod National Research Universityб Belgorod, 308015 Russia \\ ${ }^{c}$ National Research Tomsk State Universityб Tomsk, 634050 Russia \\ ${ }^{d}$ Research Institute of Medical Genetics, Tomsk National Research Medical Center, Tomsk, 634050 Russia \\ *e-mail: alekssvet2205@gmail.com
}

\begin{abstract}
The secretome of human mesenchymal stem cells (MSCs) after osteogenic differentiation of FetMSC in vitro was produced for regenerative therapy of bone tissue. The secretome was obtained from serum-free conditioned medium (SFCM) from human mesenchymal stem cells (MSCs) in vitro after osteogenic differentiation. To obtain a standard sample of large-volume SFCM FetMSC cells (700 million) were harvested in a CompacT SelecT automated system (Sartorius, UK). SFCM was concentrated by ultrafiltration, subjected to dialysis and dried in a vacuum rotary evaporator. The osteoinductive properties of the SFCM concentrate (SFCMC) in two experimental variants were studied on MSCs. No changes of the cell morphology were revealed during cultivation in the presence of SFCMC. Analysis of the expression of transcription factors Runx 2 and YAP1 (markers of osteogenic differentiation) by immunofluorescent analysis and RT-PCR demonstrated an increasing level. The results allow us to conclude that it is possible to use SFCMC from previously differentiated in the osteogenic direction MSCs to induce differentiation of other MSCs in the osteogenic direction. The effectiveness of the developed method for producing the secretome from SF$\mathrm{CM}$ of human MSCs differentiated in the osteogenic direction has been demonstrated. The obtained results showed the perspective of MSCs secretome exploration for the creation of biomedical cell products for bone restoration.
\end{abstract}

Keywords: human bone marrow mesenchymal stem cells, FetMSC cell line, osteogenic differentiation, secretome, automated cell culture station, Runx2, YAP1 